\title{
A Cross-Sectional Survey of Students and Instructors on Virtual Dermatology Teaching in a Competency-Based Format
}

\author{
Shara Chopra BS, BA,${ }^{1}$ Ankita Sinharoy, MBBS, MPH, ${ }^{2}$ Alexandra Flamm, MD ${ }^{2}$ \\ ${ }^{1}$ Penn State College of Medicine, Hershey, PA \\ ${ }^{2}$ Department of Dermatology, Penn State Milton S. Hershey Medical Center, Hershey, PA
}

\section{ABSTRACT}

Background: Due to the COVID-19 pandemic in the Spring of 2020, the dermatology rotation at the Penn State College of Medicine (PSCOM) was converted into a 4-week virtual format. Given these rapid changes, we aimed to assess student and instructor satisfaction to the virtual course and if the course fulfilled the six ACGME core-competencies for medical student education required in a traditional teaching format.

Methods: We conducted a cross-sectional study to assess PSCOM student and instructor satisfaction to the elective. Surveys specifically inquired about course learning objectives, interaction, and teaching in the virtual setting based on a 5-point Likert scale and asked the participants to provide qualitative feedback.

Results: Medical students ( $n=15$, response rate=52\%) were satisfied with learning objectives geared towards the ACGME core competencies in five of the six competencies. Instructors ( $n=7$, response rate $=58 \%$ ) reported satisfaction with convenience, university support, and technical training, but less with student-to-student interaction, gauging comprehension, and fostering critical thinking. Qualitative feedback reflected these results.

Conclusions: From our survey data, students and instructors were generally satisfied with the virtual rotation's dermatology teaching during the uncertain times of the COVID-19 pandemic and holds potential to expand dermatology education, with a future focus on improving student engagement in a virtual format.

\section{INTRODUCTION}

In a traditional in-person teaching format, student learning is assessed by whether it fulfills the ACGME (Accreditation Council for Graduate Medical Education) core competencies: patient care, medical knowledge, practice-based learning and improvement, interpersonal and communication skills, professionalism, and systems-based practice. ${ }^{1}$ During the COVID-19 pandemic, the dermatology elective at the Penn State College of Medicine (PSCOM) was converted to a four- week virtual format in lieu of a clinical rotation. Given this switch to virtual teaching, we aimed to assess fulfillment of these competencies in this learning format, as well as instructor and student satisfaction in order to identify components of virtual education that may be beneficial beyond the COVID-19 pandemic.

\section{METHODS}

We conducted a cross-sectional observational study to assess student and instructor satisfaction to the virtual November 2021 Volume 5 Issue 6 
dermatology elective from April 2020 through June 2020. PSCOM medical students (MS) were surveyed, including six MS1 (first-year) accelerated and 23 MS4 (fourth-year). Surveyed instructors were Dermatology residents (postgraduate year), including four PGY2, four PGY3, and four PGY4. Students asynchronously followed the American Academy of Dermatology's (AAD) Basic Dermatology Curriculum (https://www.aad.org/member/education/resi dents/bdc), covering morphology and the diagnosis and treatment of common skin conditions with an additional nine hours/week of course instruction. ${ }^{2,3}$ Students interacted with the PSCOM's Dermatology faculty (not surveyed) and residents in thrice-weekly virtual lectures and casebased learning, expanding on the AAD's course. Additional topics were covered in daily resident didactics, a once-weekly Journal Club, and outside assignments including considerations of ethical dilemmas in dermatology and expanding on a basic science topic. Survey tools were modified versions of previously validated instruments where participants rated satisfaction on a 5point Likert scale about course learning objectives, interaction, and virtual instruction. $4,5,6$ Qualitative feedback was also obtained. Study data were collected and managed using REDCap (Research Electronic Data Capture) tools hosted at the Penn State Health Milton S. Hershey Medical Center and PSCOM. ${ }^{7}$ This study received institutional review board exemption.

\footnotetext{
RESULTS
Twenty-nine medical students were
surveyed with 15 students responding
completely, yielding a $52 \%$ response rate.
Responses of Agree and Strongly Agree
were combined to assess satisfaction and

RESULTS
Twenty-nine medical students were
surveyed with 15 students responding
completely, yielding a $52 \%$ response rate.
Responses of Agree and Strongly Agree
were combined to assess satisfaction and

RESULTS
Twenty-nine medical students were
surveyed with 15 students responding
completely, yielding a $52 \%$ response rate.
Responses of Agree and Strongly Agree
were combined to assess satisfaction and

RESULTS
Twenty-nine medical students were
surveyed with 15 students responding
completely, yielding a $52 \%$ response rate.
Responses of Agree and Strongly Agree
were combined to assess satisfaction and

RESULTS
Twenty-nine medical students were
surveyed with 15 students responding
completely, yielding a $52 \%$ response rate.
Responses of Agree and Strongly Agree
were combined to assess satisfaction and

RESULTS
Twenty-nine medical students were
surveyed with 15 students responding
completely, yielding a $52 \%$ response rate.
Responses of Agree and Strongly Agree
were combined to assess satisfaction and
}

fulfillment of Core Competency categories. An additional student survey was partially completed and included only the Core Competency data. Student responses for learning objectives pertaining to the ACGME core competencies were averaged $(n=16)$, showed that $93.75 \%$ of students agreed the course fulfilled the competency for medical knowledge, $87.40 \%$ for patient care, $81.25 \%$ for systems-based practices, $78.75 \%$ for interpersonal and communication skills, $68.75 \%$ for professionalism, and $50 \%$ for practice-based learning and improvement. When asked if the virtual setting hindered learning $(n=15), 6.67 \%$ of students stated this was a concern for the category of medical knowledge, $20 \%$ for clinical understanding, $26.66 \%$ for communication, and $0 \%$ for professionalism.

Twelve instructors were surveyed with a $58 \%$ response rate. Instructors were satisfied with aspects of the course such as convenience, university support, technical training (100\%), and the opportunity to reach a diverse student population (85.71\%). Instructors were less satisfied with studentto-student interaction (14.29\%), gauging comprehension (14.29\%), and fostering critical thinking (28.57\%) (Table 1).

Qualitative feedback reflected objective data. Both groups enjoyed the convenience and flexibility of the course. Students and instructors reported difficulty engaging during the virtual sessions and suggested practice material, telemedicine, and reduced 
class sizes as possible ways to overcome these barriers (Table 2).

Table 1 Student and instructor satisfaction to course learning and the virtual setting.

\section{Student satisfaction}

Core

competency

Medical

knowledge

Patient care

Systems-based

practices

Interpersonal

and

communication

skills

Professionalism

Practice-based

learning and

improvement

Hindrance due to

the virtual setting

Medical

knowledge

Clinical

understanding

Communication

Professionalism

Instructor satisfaction

Virtual teaching Instructor response (\% agree; $\boldsymbol{n}=\mathbf{7}$ )

and efficacy

Student' appear

to be an online

community

Gauging

student

comprehension

Foster critical

thinking

Students are

passive in

interactions

Could not get to 85.71

know students

Diverse student

population

Content quality

Training needs

were met

Adequate tools

and support

Convenience
Student response (\% agree; $n=16$ )

93.75

87.40

81.25

78.75

68.75

50

Student response (\% agree; $\boldsymbol{n}=15$ )

6.67

20

26.66

0

14.29

14.29

28.57

85.71

85.71

85.71

100

100

100

\section{DISCUSSION}

While medical students were able to return to the clinical setting by the fall of 2020 , hybrid and virtual learning will likely continue to be an important component of dermatology education in the future. The data and opinions gleaned in this setting can be of use in improving virtual education offerings.

The patient environment continues to be indispensable as repetitive exposure aids in achieving skills of describing morphology, learning the basic skin exam, and performing diagnostic and therapeutic procedures. ${ }^{8}$ Although $93 \%$ of institutions offer a dermatology clerkship as a fourthyear elective, only on average 16.3 hours of total dermatology instruction are required in most medical curricula. ${ }^{9} \mathrm{~A}$ mixed curriculum of online didactics, self-directed learning, and in-person clinical immersion may allow for increasing the number of students exposed to dermatology clinically, especially those who may be traveling from a different campus or medical school. This represents an opportunity for reduced cost of travel and housing, while allowing students to explore the curriculum and culture of a specific dermatology program and demonstrate interest in a program. ${ }^{10}$

Classically, learning dermatology has been achieved through clinical exposure and didactic teaching sessions, with varying use of online resources. ${ }^{9}$ Adult learners, both in our course and in general, commonly enjoy the flipped classroom setting where self- 
Table 2 Qualitative feedback from students and instructors for quality improvement

\section{Student Comments}

Improve

...communication through zoom as a class is really difficult, might be easier if the class was broken into smaller groups...

Incorporate patient care somehow, possibly just having the residents carry a device in clinic with a student(s) observing on Zoom.

I would have liked more opportunity to practice knowledge of the content formally, with say a Qbank or another recommended resource.

Instructor Comments

Improve

It's a great option in current times and is more convenient. However, it's hard to gauge if the information is a good level, and the students are more reluctant to participate.

It was a great alternative, but I do not think it gives us the chance to really know the students.

directed learning and online lectures substitute traditional didactics. ${ }^{11}$ They thrive when learning has a real-world application and can participate in course structure and learning goals due to motivation from intrinsic goals. ${ }^{8}$ Continuing this style of learning in our current times can both reduce in-person sessions that must still adhere to pandemic-related restrictions and adapt to a learning style preferred by this current generation of learners.

In our course, instructors were satisfied with content, convenience, and reaching a diverse student population, but highlighted challenges engaging students and gauging comprehension. An area of weakness identified by instructors was communication and interaction with students. Possible causes include stressors posed by the pandemic, increased distractions at the home learning environment, and adapting to the new learning style. Instructors did not see their students forming an online community, yet students felt they strengthened goals related to Interpersonal and Communication Skills. This discrepancy suggests a difference in how students and

\section{Sustain}

I liked that I could create my own schedule and study plan.

I loved the grouping of the topics in each lecture and the pace that the elective was held at.... I entered my dermatology (in-person) elective much more comfortable with descriptions than I ever was before.

I enjoyed the interactive sessions led by residents as I was able to better practice what I had been learning and ensure that my knowledge and reasoning were correct.

Sustain

The convenience of online teaching is great, especially for busy residents. instructors view interactions or an element of interaction outside the virtual classroom facilitating these connections. Problembased learning and improvement showed lower satisfaction, suggesting a need for additional feedback in a virtual course. ${ }^{12}$ Reducing class sizes by half (from ten to five students), adding in-class practice material, and immersing students in virtual health encounters may improve overall satisfaction.

\section{CONCLUSION}

While limited by sample size, our course provided students with a satisfactory dermatology education that fulfilled ACGME core competencies during the uncertain times of a pandemic and supports the possibility of a virtual platform to expand dermatology education.

\section{Conflict of Interest Disclosures: None}

Funding: Penn State Department of Dermatology Marks Endowment

Corresponding Author:

Shara Chopra, BS, BA

1850 E Park Ave

November $2021 \quad$ Volume 5 Issue 6 
State College, PA, 16803

Phone: 814-404-1102

Email: schopra1@pennstatehealth.psu.edu
European Journal of Engineering Education. 2020 45:1, 4-21

\section{References:}

1. Edgar L, McLean S, Hogan S et al. The Milestones Guidebook. Accreditation Council for Graduate Medical Education (ACGME). Available at: https://www.acgme.org/Portals/0/MilestonesGuid ebook.pdf [last accessed 5 December 2020].

2. American Academy of Dermatology. Basic dermatology curriculum. Available at: https://www.aad.org/member/education/residents /bdc [last accessed 5 December 2020].

3. Regan, P. A., Kirby, J. S. Optimizing Medical Student Dermatology Education with the American Academy of Dermatology's Basic Dermatology Curriculum. SKIN The Journal of Cutaneous Medicine, 2019;3(6), 443-446.

4. Dhein CR, Noxon JO, Deykin A. Teaching the didactic aspects of ophthalmology and dermatology using an off-site instructor. $J$ Vet Med Educ. 2005;32(1):57-67.

5. Bolliger DU, Inan FA, Wasilik O. Development and validation of the online instructor satisfaction measure (OISM). Journal of Educational Technology \& Society, 2014;17(2):183-195.

6. Tschannen-Moran M, Hoy AW. Teacher efficacy: Capturing an elusive construct. Teaching and Teacher Education, 2001;17(7):783-805.

7. Harris PA, Taylor R, Thielke R et al. Research electronic data capture (REDCap)--a metadatadriven methodology and workflow process for providing translational research informatics support. J Biomed Inform. 2009; 42: 377-381.

8. Burge SM. Learning dermatology. Clin Exp Dermatol. 2004; 29: 337-40.

9. McCleskey PE, Gilson RT, DeVillez RL. Medical Student Core Curriculum in Dermatology Survey. J Am Acad Dermatol. 2009; 61: 30-5.

10. Adusumilli NC, Kalen J, Hausmann K, Friedman AJ. Dermatology applicant perspectives of a virtual visiting rotation in the era of COVID-19. Journal of the American Academy of Dermatology. 2021;84(6):1699-701.

11. Svoboda, S. A., Swigert, A., Nielson, C. B., Motaparthi, K. Inspired by COVID-19 isolation: Evolving educational techniques in dermatology residency programs. Clinics in Dermatology, 2021;39(1), 41-44.

12. Meikleham A, Hugo R. Understanding informal feedback to improve online course design. 